\title{
Palinotaxonomia de Besleria L. e Napeanthus Gardn. (Beslerieae/Napeantheae - Gesneriaceae) com ênfase nas espécies ocorrentes no Estado de São Paulo ${ }^{1}$
}

\author{
EDUARDO CUSTÓDIO GASPARINO ${ }^{2,6}$, MARIA AMÉLIA VITORINO DA CRUZ-BARROS ${ }^{3}$, \\ ALAIN CHAUTEMS ${ }^{4}$ e SILVIA REGINA GALLETI ${ }^{5}$
}

(recebido: 23 de fevereiro de 2011; aceito: 07 de junho de 2011)

\begin{abstract}
Palynotaxonomy of Besleria L. and Napeanthus Gardn. (Beslerieae/Napeantheae - Gesneriaceae) specially species occurring in São Paulo State). This paper presents a study of the pollen grains of three species of Besleria L. (B. longimucronata Hoehne, B. selloana Klotzsch \& Hanst., B. umbrosa Mart.) and one of Napeanthus (Napeanthus primulifolius (Raddi) Sandw.) from São Paulo state and Napeanthus reitzii (L. B. Sm.) B. L. Burtt ex Leeuwenb. occurring in southern Brazil. The pollen material was acetolysed, measured, described and illustrated using light microscopy. For further details of pollen surface and exine, non-acetolysed pollen grains were analyzed by means of scanning and transmission electron microscopy. The pollen grains of Besleria and Napeanthus are small to medium size, isopolar, oblate spheroidal, 3-colporate, endoaperture lolongate, psilate-perforate (B. longimucronata), rugulate (B. umbrosa) and microreticulate (B. selloana, N. primulifolius e N. reitzii). The results demonstrated the taxonomic importance of pollen morphology studies corroborating with the subdivision of the taxa in these tribes.
\end{abstract}

Key words - morphology, pollen, taxonomy

RESUMO - (Palinotaxonomia de Besleria L. e Napeanthus Gardn. (Beslerieae/Napeantheae - Gesneriaceae) com ênfase nas espécies ocorrentes no Estado de São Paulo) - Foi apresentado o estudo polínico de três espécies de Besleria L. (B. longimucronata Hoehne, B. selloana Klotzsch \& Hanst., B. umbrosa Mart.) e uma espécie de Napeanthus (Napeanthus primulifolius (Raddi) Sandw.) ocorrentes no Estado de São Paulo, além de Napeanthus reitzii (L. B. Sm.) B. L. Burtt ex Leeuwenb. que ocorre no Sul do Brasil. Os grãos de pólen foram acetolisados, medidos, descritos e fotomicrografados sob microscopia de luz. Para observar detalhes da ornamentação e estrutura da exina, grãos de pólen não acetolisados foram analisados em microscopia eletrônica de varredura e de transmissão. As medidas receberam tratamento estatístico. Os grãos de pólen foram descritos como pequenos a médios, isopolares, oblato-esferoidais, 3-colporados, endoaberturas lolongadas, psilado-perfurados (B. longimucronata), rugulados (B. umbrosa) ou microrreticulados (B. selloana, N. primulifolius e $N$. reitzii). Os resultados obtidos demonstram a importância taxonômica da morfologia polínica para corroborar a subdivisão dos táxons nas tribos Beslerieae e Napeantheae.

Palavras-chave - grãos de pólen, morfologia, taxonomia

\section{Introdução}

Gesneriaceae com cerca de 150 gêneros e mais de 3.000 espécies (Weber 2004a), é uma família pantropical com ampla distribuição em todo o Mundo, estando bem representada nos trópicos e com poucas

1. Parte da tese de doutorado do primeiro autor, Programa de PósGraduação em Biodiversidade Vegetal e Meio Ambiente, Instituto de Botânica, São Paulo, SP, Brasil.

2. Universidade Estadual Paulista, Faculdade de Ciências Agrárias e Veterinárias, Departamento de Biologia Aplicada à Agropecuária, Via de acesso Prof. Paulo Donato Castellane, 14884-900 Jaboticabal, SP, Brasil.

3. Instituto de Botânica, Núcleo de Pesquisas em Palinologia, Caixa Postal 68041, 04045-972, São Paulo, SP, Brasil.

4. Conservatoire et Jardin Botaniques de La Ville de Genève, C.P. 60, CH-1292, Chambésy, Genève, Suisse.

5. Instituto Biológico, Laboratório de Microscopia Eletrônica, CPDSV, Caixa Postal 12898, 04014-002 São Paulo, SP, Brasil.

6._Autor para correspondência: ecgasparino@fcav.unesp.br espécies nativas em regiões temperadas (Burtt \& Wiehler 1995).

A família pode ser dividida em três grupos naturais ou subfamílias, Coronantheroideae, Gesnerioideae e Cyrtandroideae, com distribuição, respectivamente, nas regiões Sul Pacífica, Neotropical e Paleotropical (Wiehler 1983, Burtt \& Wiehler 1995). No Brasil, a família é representada por 220 espécies distribuídas em 23 gêneros (Chautems 1991, Chautems \& Matsuoka 2003). A maior concentração de táxons se encontra na região Sudeste (Barroso et al. 1986), principalmente em regiões úmidas da Mata Atlântica e algumas vezes na região amazônica (Meirelles et al. 1999, Safford \& Martinelli 2000), sendo também nativas de campos rupestres de planalto (Chautems 1991, Chautems 2003).

Inicialmente, Gesnerioideae foi subdividida por Wiehler (1983) em cinco tribos, Beslerieae, Episcieae, Gesnerieae, Gloxinieae e Napeantheae, todas com 
gêneros neotropicais; atualmente, com base nos trabalhos de análises moleculares, a subfamília encontra-se dividida em oito tribos: Beslerieae, Coronanthereae, Episcieae, Gesnerieae, Gloxinieae, Napeantheae, Sinningieae e Sphaerorrhizeae (Smith et al. 1997, Smith 2000, Zimmer et al. 2002, Roalson et al. 2005 a, b).

Segundo Weber(2004a), a tribo Beslerieae possui sete gêneros: Anetanthus Benth., Besleria L., Cremosperma Benth., Gasteranthus Benth., Reldia Wiehler, Resia $\mathrm{H}$. E. Moore e Tylopsacas Leeuwenb., sendo heterogênea e fracamente definida (Smith 1996, 2000, Smith et al. 1997). Sua inflorescência não possui brácteas o que difere de todas as outras tribos em Gesnerioideae (Wiehler 1975, 1983, Skog \& Jesus 1997).

Besleria L., o principal gênero da tribo, possui cerca de 200 espécies, ocorrendo em todo o neotrópico, desde o México, Ilhas do Caribe até a Bolívia. O gênero possui como centro de diversidade os Andes da Colômbia e o Equador, com algumas espécies endêmicas no sudeste brasileiro (Wiehler 1983, 1975, Weber 2004a).

Taxonomicamente, Besleria foi subdividido por Morton (1939) em quatro seções: Eubesleria (Hanst.) Benth. \& Hook., Rhynchobesleria (Hanst.) Benth. \& Hook., Gasteranthus (Benth.) Benth. \& Hook. e Neobesleria Morton. Atualmente o gênero possui três seções, já que Wiehler (1975) segregou as espécies da seção Gasteranthus e algumas espécies de Neobesleria para reestabelecer o gênero Gasteranthus Benth., um gênero descrito por Bentham (1846) que havia sido tratado, até então, como parte de Besleria (Hanstein 1865, Bentham 1876, Morton 1939, Skog \& Kvist 2000).

As características do fruto ajudam no posicionamento do gênero Besleria dentro de Beslerieae, pois, apesar dos representantes de Episcieae (como Codonanthe (Mart.) Hanst., Columnea L., Corytoplectus Oerst., Dalbergaria Tussac, Neomortonia Wiehler, Rufodorsia Wiehler, Pentadenia (Planch.) Hanst. e Trichantha Hook.) também possuírem fruto baga, em Besleria a polpa do fruto é derivada do tecido da placenta enquanto que nos gêneros de Episcieae esta provém do tecido funicular (Wiehler 1975, 1983, Smith 2000, Weber 2004a).

Napeantheae Wiehler é uma tribo monotípica de Gesnerioideae apresentando 30 espécies nos neotrópicos. Com base principalmente em dados moleculares, verificou-se que Napeantheae é muito relacionada com Beslerieae, e que estas duas tribos formam um clado irmão com as Gesneroideae restantes (Smith 2000, Zimmer et al. 2002). Folhas rosuladas, ausência de nectário e o fruto em cápsula loculicida são alguns dos caracteres que diferenciam Napeanthus dos outros gêneros de Gesnerioideae (Feuillet \& Skog 2002, Weber 2004a).

Até o presente momento poucos autores estudaram a morfologia polínica de espécies brasileiras de Gesneriaceae sendo, portanto escassos os dados palinológicos sobre a família, principalmente sobre a subfamília Gesnerioideae e os gêneros Besleria e Napeanthus. Existem dados polínicos para Gesneriaceae nos trabalhos de Erdtman (1952), Campos (1962), Melhem \& Mauro (1973), Salgado-Labouriau (1973), Nowicke (1974), Howard (1975), Skog (1976), Williams (1978), Felice et al. (1981), Fritze \& Williams (1988), Roubik \& Moreno (1991), Luegmayr (1993a, b), ZhiJian et al. (1995, 1997), Xifreda (1996), Schlag-Edler \& Kiehn (2001), Melhem et al. (2003), Palee et al. (2003), Weber (2004b) e Fourny et al. (2010).

Este trabalho teve como objetivo a caracterização da morfologia polínica dos gêneros Besleria L. ( $B$. longimucronata Hoehne, B. selloana Klotzsch \& Hanst., B. umbrosa Mart.) e Napeanthus Gardn. (N. primulifolius (Raddi) Sandwith) ocorrentes no Estado de São Paulo, visando fornecer subsídio para a taxonomia da família. A espécie Napeanthus reitzii, embora não ocorra no Estado, foi introduzida no trabalho visando caracterizar os grãos de pólen das duas únicas espécies brasileiras do gênero.

\section{Material e métodos}

Os materiais polínicos analisados foram retirados de exsicatas depositadas nos Herbários UEC (Herbário da Universidade Estadual de Campinas) e SP (Herbário do Estado "Maria Eneyda P. Kauffmann Fidalgo"), utilizandose material coletado não só no Estado de São Paulo, como em outros estados, quando se tratava do único espécime com botões florais disponíveis. Um deles foi tomado como material padrão (assinalado com asterisco na listagem abaixo), no qual foram efetuadas todas as medidas e observações necessárias para a caracterização dos grãos de pólen. Os demais espécimes foram utilizados como materiais de comparação.

Besleria longimucronata: BRASIL. São PAULO: Caraguatatuba, rumo a São José dos Campos, 28-VII-1983, J.R. Pirani \& O. Yano 781 (SP); São Sebastião, Fazenda Jaraguá, 30-VI-1956, M. Kuhlmann \& A. Trincado 3858 (SP); Ubatuba, estação experimental do Instituto Agronômico, 12VIII-1977, P.E. Gibbs \& H.F. Leitão Filho 5657 (UEC); idem, Pontal da Lagoinha, 31-VIII-1980, E. Forero 7679 (SP); idem, estrada Ubatuba-São Luiz de Paraitinga, 18-VIII-1987, M. Kirizawa \& E. Ieda 1866 (SP); idem, morro próximo à praia da Enseada, 8-IX-1989, S. Romaniuc Neto \& I. Cordeiro 1053 (SP); idem, núcleo Picinguaba, 10-XI-1993, F. Barros 2843 (SP)*; idem, trilha da praia da Tabatinga, 16-IX-2000, $P$. Fiaschi et al. 436 (SP). Rio DE JANEIRO: Parati, estrada Parati- 
Cunha, 20-VIII-1987, M. Kirizawa \& E. Ieda 1892 (SP). B. selloana: BRASIL. São PAulo: Mogi das Cruzes, Serra do Mar, 28-VII-1983, M. Kirizawa et al. 1017 (SP); idem, Serra do Mar, 16-IX-1983, M. Kirizawa et al. 1057 (SP); São Paulo, Alto da Serra, 28-VIII-1918, F.C. Hoehne 2374 (SP)*. B. umbrosa: BRASIL. São PAUlo: Bananal, estrada de acesso à Reserva Florestal, 23-X-1979, W. Mantovani 154 (SP); Pindamonhangaba, subosque mata de altitude, 11-XI-1953, M. Kuhlmann 2903 (SP). BRASIL: Rio DE JANEIRO: Resende, próximo à cachoeira do Alcantilado, 24-VI-1994, L. Rossi \& O.T. Oyakawa 1532 (SP)*. Napeanthus primulifolius: BRASIL: São PAulo: Cananéia, Ilha do Cardoso, 6-XII-1990, F. Barros \& J.E.L.S. Ribeiro 2100 (SP)*; Ubatuba, Estação Experimental, 17-XI-1998, C. Kameyama et al. 113 (SP). N. reitzii: BRASIL. PARANÁ: Morretes, Pico do Marumbi, 23-I1999, C. Kozera \& V.A.O. Dittrich 910 (UEC)*.

Os materiais polínicos foram preparados pelo método de acetólise de Erdtman (1960), acrescido das modificações citadas em Melhem et al. (2003) e medidos até sete dias após sua preparação (Salgado-Labouriau et al. 1965).

No material padrão, foram feitas 25 medidas dos diâmetros dos grãos de pólen tomados ao acaso, e calculadas a média aritmética $(\bar{x})$, o desvio padrão da média $\left(s_{\bar{x}}\right)$, o desvio padrão da amostra $(s)$, o coeficiente de variabilidade $(\mathrm{V})$ e o intervalo de confiança (IC) a 95\%. Para as medidas dos demais caracteres, como aberturas e camadas da exina, bem como para os diâmetros dos materiais de comparação, foram calculadas somente as médias aritméticas de 10 medidas. Além do intervalo de confiança a 95\%, foram feitas comparações das medidas dos diâmetros dos grãos de pólen mediante análise de variância seguida do teste de Tukey, considerando-se a diferença mínima significativa ao nível de 5\% (Vieira 1981, Zar 1996). Para as espécies de Napeanthus foram utilizados o intervalo de confiança e o teste T (Vieira 1981). Esses dados foram representados por gráficos usando o pacote estatístico MINITAB 10.3 for Windows (2003). Os resultados finais do teste de Tukey foram representados por linhas horizontais na parte superior dos gráficos dos intervalos de confiança, unindo os valores que não se apresentaram significativamente diferentes.

Para a análise dos grãos de pólen em microscopia eletrônica de varredura (MEV) foi utilizada a metodologia descrita em Melhem et al. 2003, para grãos de pólen não acetolisados. Já a técnica de preparação dos grãos de pólen para microscopia eletrônica de transmissão seguiu o proposto por Sabatini et al. (1963) e Haddad et al. (1998).

As fotomicrografias digitais em microscopia de luz (ML) foram realizadas com grãos de pólen acetolisados utilizando-se um microscópio óptico Olympus BX50, com câmara de vídeo (Sony Camera adaptor CMA-D2) acoplada e um microcomputador PC utilizando-se o programa Image Pro-plus versão 3.0 for Windows. Já para a análise de microscopia eletrônica de varredura e microscopia eletrônica de transmissão foram utilizados, respectivamente, um microscópio Philips XL Serie XL 20, S/W, ver. 5.21 e um microscópio Philips em 208.
Foi utilizada a análise de componentes principais (PCA) para avaliar se o conjunto das medidas permitia separar as espécies entre si, tomando como base as medidas obtidas a partir do material padrão. Esta análise foi realizada inicialmente com a utilização do programa FITOPAC (Shepherd 1996), para a transformação das medidas métricas dos grãos de pólen pelo logaritmo natural $[\log (\mathrm{x}+1)] \mathrm{e}$, posteriormente, do programa PC-ORD versão 7 (McCune \& Mefford 1999) para a ordenação a partir de matriz de covariância.

Os termos polínicos utilizados nas descrições dos grãos de pólen baseiam-se nos glossários de Barth \& Melhem (1988) e Punt et al. (2007), enquanto que as classes do índice de área polar (IAP) seguem Faegri \& Iversen (1966).

\section{Resultados}

Os gêneros Besleria (figuras 1-17) e Napeanthus (figuras 18-27) são caracterizados por apresentarem grãos de pólen pequenos ou médios ( $B$. selloana, tabelas 1-2), isopolares, âmbito circular (figuras 1, 18, 25,) a subcircular (Besleria selloana, B. umbrosa, figuras 6, 11); com área polar muito pequena (Besleria) a pequena (Napeanthus); oblato-esferoidais; 3-colporados, colpos longos (figuras 2, 7, 15, 19, tabela 2), endoaberturas lolongadas (figura 7, tabela 2), às vezes de difícil visualização e mensuração (Napeanthus, figura 19); exina tectada, psilado-perfurada (B. longimucronata, figura 4), rugulada (B. umbrosa, figuras 14-16) a semitectada, microrreticulada, homobrocada ( $B$. selloana, figuras 8-9) ou heterobrocada (Napeanthus, figuras 21-23), muros psilados, largos, retos (B. selloana) ou sinuosos (Napeanthus primulifolius, N. reitzii, figura 23), simplescolumelados, lúmens arredondados. Sexina mais espessa que a nexina (tabela 2), a qual diferencia-se em nexina 1 e nexina 2 (figuras 5, 10, 17, 24).

Colpos longos, largos (B. selloana) a estreitos, constritos na região mediana (B. selloana) ou não, com extremidades afiladas (B. longimucronata, Napeanthus primulifolius, $N$. reitzii, figuras 1,21 ) ou arredondadas (figura 6). Sob MEV observam-se colpos e endoaberturas com membrana ornamentada por grânulos (figuras 9, 14$15,21)$. Verifica-se, na tabela 2 , que os maiores valores de colpos, comprimento de endoabertura e exina total são encontrados nos grãos de pólen de Besleria selloana, enquanto que os maiores valores para a largura das endoaberturas ocorrem nos grãos de pólen de Besleria longimucronata (tabela 2). Já nas espécies de Napeanthus (tabela 2), os grãos de pólen de $N$. primulifolius apresentam os colpos mais largos, enquanto que os de $N$. reitzii possuem os maiores valores de endoaberturas e comprimento dos colpos. Os valores de exina total são similares para as espécies do gênero Napeanthus. 

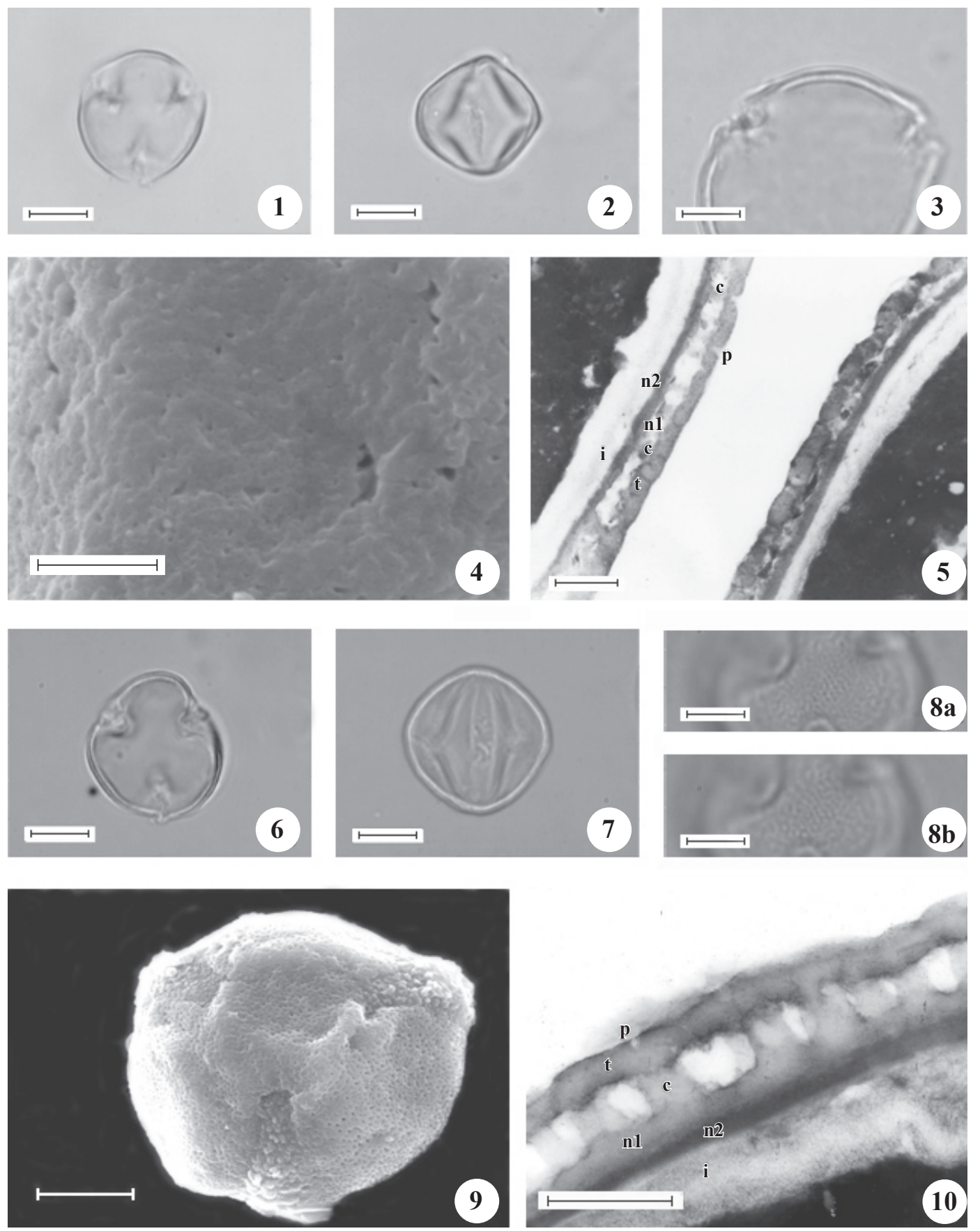

Figuras 1-10. Fotomicrografias e eletromicrografias (MEV e MET) dos grãos de pólen de espécies de Besleria. 1-5. Besleria longimucronata. 1. Vista polar. 2. Vista equatorial. 3. Corte óptico. 4. Detalhe da ornamentação (MEV). 5. Detalhe da estrutura da parede, sob MET ( $\mathrm{i}=$ intina, $\mathrm{c}=$ columela, $\mathrm{n} 1=$ nexina $1, \mathrm{n} 2=$ nexina $2, \mathrm{p}=$ perfuração, $\mathrm{t}=$ teto). 6-10. Besleria selloana . 6. Vista polar. 7. Vista equatorial. 8. Análise de L.O. 9. Vista polar (MEV). 10. Detalhe da estrutura da parede, sob MET ( $\mathrm{i}=$ intina; $\mathrm{c}=$ columela; $\mathrm{n} 1=$ nexina $1 ; \mathrm{n} 2=$ nexina $2 ; \mathrm{p}=$ perfuração; $\mathrm{t}=$ teto). Barra $=10 \mu \mathrm{m}(1-2,6-7) ; 5 \mu \mathrm{m}(3,8-9) ; 2 \mu \mathrm{m}$ (4); $500 \mathrm{~nm}(5) ; 750 \mathrm{~nm}(10)$.

Figures 1-10. Light, scanning and transmition electron micrographs of pollen grains of Besleria. 1-5. Besleria longimucronata. 1. Polar view. 2. Equatorial view. 3. Optical section. 4. Detail of ornamentation (SEM). 5. Detail of pollen wall structure in TEM ( $\mathrm{i}=$ intine, $\mathrm{c}=$ columella, $\mathrm{n} 1=$ nexine $1, \mathrm{n} 2=$ nexine $2, \mathrm{p}=$ perforation, $\mathrm{t}=$ tectum). $6-10$. Besleria selloana. 6 . Polar view. 7. Equatorial view. 8. Analysis of L.O. 9. Polar view (SEM). 10. Detail of pollen wall structure in TEM $(\mathrm{I}=$ intine; $\mathrm{c}=$ columella; $\mathrm{n} 1=$ nexina $1 ; \mathrm{n} 2=$ nexina $2 ; \mathrm{p}=$ perforation; $\mathrm{t}=$ tectum $) . \mathrm{Bar}=10 \mu \mathrm{m}(1-2,6-7) ; 5 \mu \mathrm{m}(3,8-9) ; 2 \mu \mathrm{m}(4)$; $500 \mathrm{~nm}(5) ; 750 \mathrm{~nm}(10)$. 

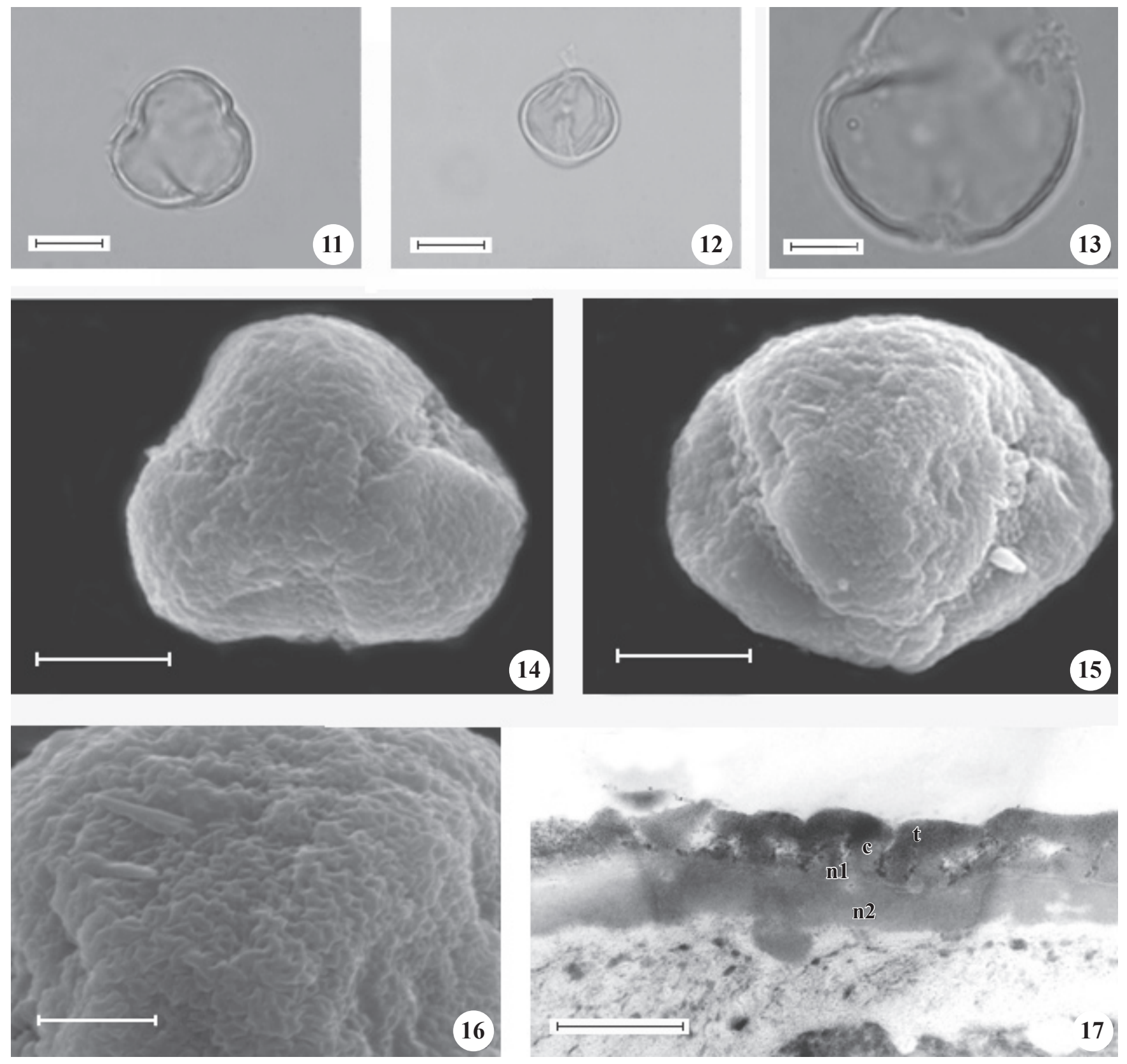

Figuras 11-17. Fotomicrografias e eletromicrografias (MEV e MET) dos grãos de pólen de espécimes de Besleria umbrosa. 11. Vista polar. 12. Vista equatorial. 13. Corte óptico. 14. Vista polar (MEV). 15. Vista equatorial (MEV). 16. Detalhe da ornamentação (MEV). 17. Detalhe da estrutura da parede da exina sob MET $(\mathrm{t}=$ teto; $\mathrm{c}=$ columela; $\mathrm{n} 1=$ nexina $1 ; \mathrm{n} 2=$ nexina 2). Barra $=10 \mu \mathrm{m}(11-12) ; 5 \mu \mathrm{m}(13-15) ; 2 \mu \mathrm{m}(16) ; 500 \mathrm{~nm}$ (17).

Figures 11-17. Light, scanning and transmition electron micrographs of pollen grains of Besleria umbrosa specimens. 11. Polar view. 12. Equatorial view. 13. Optical section. 14. Polar view (SEM). 15. Equatorial view (SEM). 16. Detail of ornamentation (SEM). 17. Detail of pollen wall structure in TEM $(\mathrm{t}=$ tectum; $\mathrm{c}=$ columella; $\mathrm{n} 1=$ nexine $1 ; \mathrm{n} 2=$ nexine 2$)$. Bar $=10 \mu \mathrm{m}$ (11-12); $5 \mu \mathrm{m}(13-15) ; 2 \mu \mathrm{m}(16) ; 500 \mathrm{~nm}(17)$.

Sob MEV, percebe-se em Besleria longimucronata (figura 4), exina levemente ondulada com perfurações esparsas, enquanto que em B. umbrosa (figuras 15-17) nota-se que a exina apresenta ondulações mais evidentes, espalhadas por toda a superfície do grão de pólen, parecendo rúgulas; já em Besleria selloana (figura 9) e Napeanthus primulifolius (figura 21-23), observa-se ornamentação microrreticulada.

Sob MET, nota-se em B. longimucronata (figura 5), um teto contínuo, com algumas perfurações, mais 
Tabela 1. Caracterização morfológica dos grãos de pólen de espécies de Besleria L. e Napeanthus Gardn. ( $\mathrm{P}=$ pequeno; $\mathrm{M}=$ médio; $\mathrm{OE}=$ oblato-esferoidal; $\mathrm{P} / \mathrm{E}=$ relação entre o diâmetro polar e o diâmetro equatorial).

Table 1. Morphologic characterization of Besleria L. and Napeanthus Gardn. pollen grains. $(\mathrm{P}=$ small; $\mathrm{M}=$ medium; $\mathrm{OE}=$ oblate spheroidal; $\mathrm{P} / \mathrm{E}=$ ratio between polar diameter and equatorial diameter).

\begin{tabular}{lccccl}
\hline Espécies & Tamanho & P/E & Forma & Cólporos & Exina \\
\hline Besleria longimucronata & $\mathrm{P}$ & 0,91 & $\mathrm{OE}$ & 3 & Perfurado- psilada \\
Besleria selloana & $\mathrm{P}-\mathrm{M}$ & 0,99 & $\mathrm{OE}$ & 3 & Microrreticulada \\
Besleria umbrosa & $\mathrm{P}$ & 0,91 & $\mathrm{OE}$ & 3 & Rugulada \\
Napeanthus primulifolius & $\mathrm{P}$ & 0,93 & $\mathrm{OE}$ & 3 & Microrreticulada \\
Napeanthus reitzii & $\mathrm{P}$ & 0,93 & $\mathrm{OE}$ & 3 & Microrreticulada \\
\hline
\end{tabular}

Tabela 2. Dados quantitativos dos grãos de pólen de espécies de Besleria L. e Napeanthus Gardn. em vista equatorial e polar. ( $\mathrm{VE}=$ vista equatorial; $\mathrm{VP}=$ vista polar; $\mathrm{FV}=$ faixa de variação; $\bar{x}=$ média; $s_{\bar{x}}=$ desvio padrão da média; $s=$ desvio padrão da amostra; $\mathrm{V}=$ coeficiente de variabilidade; $\mathrm{IC}=$ intervalo de confiança a $95 \%$; IAP = índice de área polar).

Table 2. Quantitative data of pollen grains of Besleria L. and Napeanthus Gardn. species in equatorial and polar views. (VE $=$ equatorial view; $\mathrm{VP}=$ polar view; $\mathrm{FV}=$ variation interval; $\bar{x}=$ mean; $s_{\bar{x}}=$ standard error; $s=$ standard deviation; $\mathrm{V}=$ coefficient of variation; IC = confidential interval in $95 \%$; IAP = index of polar area).

\begin{tabular}{|c|c|c|c|c|c|c|}
\hline $\begin{array}{l}\text { Grandezas/ } \\
\text { Espécies }\end{array}$ & & $\begin{array}{c}\text { Besleria } \\
\text { longimucronata }\end{array}$ & B. selloana & B. umbrosa & $\begin{array}{l}\text { Napeanthus } \\
\text { primulifolius }\end{array}$ & N. reitzii \\
\hline Diâmetro & $\mathrm{FV}(\mu \mathrm{m})$ & $19,58-23,24$ & $21,16-26,66$ & $19,49-23,24$ & $16,66-18,99$ & $16,16-22,82$ \\
\hline Polar & $\bar{x} \pm s_{\bar{x}}(\mu \mathrm{m})$ & $21,21 \pm 0,19$ & $24,39 \pm 0,27$ & $21,59 \pm 0,19$ & $17,86 \pm 0,13$ & $19,71 \pm 0,32$ \\
\hline \multirow[t]{3}{*}{ (VE) } & $s(\mu \mathrm{m})$ & 0,95 & 1,35 & 0,94 & 0,64 & 1,58 \\
\hline & V $(\%)$ & 4,47 & 5,54 & 4,36 & 3,57 & 8,00 \\
\hline & $\mathrm{IC}(\mu \mathrm{m})$ & $20,82-21,60$ & $23,83-24,95$ & $21,20-21,98$ & $17,59-18,13$ & $19,05-20,37$ \\
\hline Diâmetro & $\mathrm{FV}(\mu \mathrm{m})$ & $21,49-26,16$ & $21,82-26,74$ & $21,91-25,32$ & $17,41-20,59$ & $18,33-22,74$ \\
\hline Equatorial & $\bar{x} \pm s_{\bar{x}}(\mu \mathrm{m})$ & $23,43 \pm 0,23$ & $24,64 \pm 0,28$ & $23,68 \pm 0,19$ & $19,14 \pm 0,17$ & $21,16 \pm 0,20$ \\
\hline \multirow[t]{3}{*}{ (VE) } & $s(\mu \mathrm{m})$ & 1,16 & 1,42 & 0,97 & 0,84 & 1,00 \\
\hline & V (\%) & 4,95 & 5,78 & 4,11 & 4,37 & 4,71 \\
\hline & $\mathrm{IC}(\mu \mathrm{m})$ & $22,96-23,90$ & $24,06-25,22$ & $23,29-24,07$ & $18,79-19,49$ & $20,75-21,57$ \\
\hline Diâmetro & $\mathrm{FV}(\mu \mathrm{m})$ & $20,41-25,49$ & $21,99-26,74$ & $20,58-25,74$ & $16,66-20,66$ & $18,49-22,41$ \\
\hline Equatorial & $\bar{x} \pm s_{\bar{x}}(\mu \mathrm{m})$ & $22,85 \pm 0,26$ & $24,60 \pm 0,22$ & $22,74 \pm 0,29$ & $18,77 \pm 0,19$ & $20,96 \pm 0,21$ \\
\hline \multirow[t]{3}{*}{ (VP) } & $s(\mu \mathrm{m})$ & 1,30 & 1,12 & 1,43 & 0,96 & 1,07 \\
\hline & $\mathrm{V} \%$ & 5,69 & 4,56 & 6,31 & 5,14 & 5,10 \\
\hline & $\mathrm{IC}(\mu \mathrm{m})$ & $22,31-23,39$ & $24,15-25,05$ & $22,14-23,34$ & $18,38-19,16$ & $20,53-21,39$ \\
\hline Apocolpia & $\bar{x}(\mu \mathrm{m})$ & 5,86 & 5,51 & 5,28 & 5,06 & 6,60 \\
\hline IAP & $\bar{x}(\mu \mathrm{m})$ & 0,25 & 0,22 & 0,23 & 0,27 & 0,31 \\
\hline \multicolumn{7}{|l|}{ Cólporo } \\
\hline comprimento & $\bar{x}(\mu \mathrm{m})$ & 17,08 & 19,10 & 17,99 & 13,12 & 14,04 \\
\hline largura & $\bar{x}(\mu \mathrm{m})$ & 1,67 & 2,49 & 1,87 & 1,52 & 1,36 \\
\hline \multicolumn{7}{|l|}{ Endoabertura } \\
\hline comprimento & $\bar{x}(\mu \mathrm{m})$ & 4,18 & 4,22 & 3,30 & 3,08 & 3,62 \\
\hline largura & $\bar{x}(\mu \mathrm{m})$ & 3,22 & 3,07 & 3,09 & 1,92 & 2,56 \\
\hline Exina & $\bar{x}(\mu \mathrm{m})$ & 1,15 & 1,21 & 1,17 & 1,29 & 1,29 \\
\hline Sexina & $\bar{x}(\mu \mathrm{m})$ & 0,75 & 0,81 & 0,76 & 0,88 & 0,86 \\
\hline Nexina & $\bar{x}(\mu \mathrm{m})$ & 0,40 & 0,40 & 0,41 & 0,42 & 0,44 \\
\hline Teto & $\bar{x}(\mu \mathrm{m})$ & 0,43 & 0,42 & 0,38 & 0,48 & 0,41 \\
\hline
\end{tabular}


espesso que a nexina, e sustentado por columelas curtas e pouco nítidas. Às vezes, os espaços intercolumelares são bem reduzidos ou quase não visualizados e ocupados por material do tapete. A nexina é diferenciada em nexina 1 (mais delgada) e nexina 2 (mais espessa). Intina espessa. Nos grãos de pólen de B. selloana (figura 10), observa-se um teto compacto, espesso, levemente ondulado, com perfurações. Nexina nitidamente subdividida em nexina 1 (mais espessa) e nexina 2 (mais delgada). Camada infratectal com columelas espessadas, de diferentes diâmetros. Já nos grãos de pólen de $B$. umbrosa (figura 17) percebe-se um teto mais ondulado, compacto, com perfurações; columelas pouco nítidas devido a presença de material do tapete entre estas. Nexina mais espessa que o teto e subdividida em nexina 1 (mais delgada) e nexina 2 (mais espessa). Nas três espécies de Besleria a intina é quase sempre mais espessa que a exina. Nota-se nos grãos de pólen de Napeanthus primulifolius (figura 24) um teto descontínuo, mais espesso que a nexina, com algumas ondulações tanto na superfície externa quanto na superfície voltada para o espaço intercolumelar; a camada columelar é irregular, com columelas incompletas que partem da nexina não atingindo o teto ou que partem do teto e não atingem a nexina; as columelas inteiras apresentam diâmetros diferentes. Nexina compacta subdividida em nexina 1 (extremamente delgada) e nexina 2 (quase tão espessa quanto o teto). Intina espessa.

Quanto ao tamanho, algumas distinções podem ser feitas, conforme se constata na representação gráfica do intervalo de confiança e do teste de Tukey (figura 28). Observa-se que os diâmetros dos grãos de pólen do gênero Napeanthus são menores que os de Besleria. Nota-se, também, que Besleria selloana tem grãos de pólen significativamente maiores, enquanto que em Napeanthus primulifolius estes são significativamente menores. Em B. longimucronata e B. umbrosa os grãos de pólen não se separam entre si, contudo em Napeanthus reitzii estes se separam significativamente dos das demais espécies.

Na tabela 3, observa-se que a grande maioria dos espécimes de comparação aqui analisados, de Besleria e Napeanthus, apresenta valores dos diâmetros em vista polar e equatorial dentro da faixa de variação do seu respectivo material padrão, com exceção apenas do espécime S. Romaniuc Neto \& I. Cordeiro 1053 de Besleria longimucronata cujas dimensões de todos os diâmetros dos grãos de pólen são bem distintas e estão fora da faixa de variação.

Quanto à forma (tabela 3), os espécimes de comparação M. Kirizawa \& E. Ieda 1892 e J.R. Pirani \&
Tabela 3. Média aritmética (em $\mu \mathrm{m})$ das medidas dos diâmetros polar (DP) e equatorial (DE) em vista equatorial e dos diâmetros equatorial em vista polar (EVP), dos grãos de pólen de espécies de Besleria L. e Napeanthus Gardn., dos materiais de comparação $(n=10)$. ( $\mathbf{\square}=$ valor dentro do IC do espécime padrão; = valor fora do IC, mas dentro da FV do espécime padrão; $\boldsymbol{\Lambda}$ = valor fora da $\mathrm{FV} ; \mathrm{P}=$ diâmetro polar; $\mathrm{E}=$ diâmetro equatorial).

Table 3. Mean $(\mu \mathrm{m})$ of polar diameter (DP) and equatorial diameter (DE) in equatorial view, and equatorial diameter in polar view (EVP) of comparison specimes of Besleria $\mathrm{L}$. and Napeanthus Gardn. species $(n=10)$. $(\mathbf{\square}=$ value inside IC of standard specimen; = value out IC, but inside FV of standard specimen; $\boldsymbol{\Lambda}=$ value out $\mathrm{FV} ; \mathrm{P}=$ polar diameter; $\mathrm{E}=$ equatorial diameter).

\begin{tabular}{|c|c|c|c|c|}
\hline Espécie/material testemunho & DP & $\mathrm{DE}$ & EVP & $\mathrm{P} / \mathrm{E}$ \\
\hline \multicolumn{5}{|l|}{ B. longimucronata } \\
\hline P. Fiaschi et al. 436 & 20,03 • & $21,76^{\bullet}$ & $21,54^{\bullet}$ & 0,92 \\
\hline E. Forero 7679 & $24,83^{\wedge}$ & $25,96^{\bullet}$ & $25,13^{\bullet}$ & 0,95 \\
\hline $\begin{array}{l}\text { P.E. Gibbs \& H.F. Leitão } \\
\text { Filho } 5657\end{array}$ & 21,31 • & $23,10^{\text {॥ }}$ & $23,80^{\bullet}$ & 0,92 \\
\hline $\begin{array}{l}\text { M. Kirizawa \& E. Ieda } \\
\quad 1866\end{array}$ & $19,64^{\bullet}$ & $20,06^{\boldsymbol{\Lambda}}$ & $19,73^{\wedge}$ & 0,98 \\
\hline $\begin{array}{l}\text { M. Kirizawa \& E. Ieda } \\
1892\end{array}$ & $19,45^{\wedge}$ & $22,65^{\bullet}$ & $21,72 \bullet$ & 0,86 \\
\hline $\begin{array}{l}\text { M. Kuhlmann \& A. } \\
\text { Trincado } 3858\end{array}$ & $19,42^{\wedge}$ & $21,52 \bullet$ & $21,51^{\bullet}$ & 0,90 \\
\hline J.R. Pirani \& O. Yano 781 & $18,46^{\mathbf{\Delta}}$ & $21,96^{\star}$ & $20,20^{\wedge}$ & 0,84 \\
\hline $\begin{array}{l}\text { S. Romaniuc Neto \& } \\
\text { I. Cordeiro } 1053\end{array}$ & $25,53^{\wedge}$ & $27,35^{\mathbf{\Delta}}$ & $28,13^{\wedge}$ & 0,93 \\
\hline \multicolumn{5}{|l|}{ B. selloana } \\
\hline M. Kirizawa et al. 1017 & $22,31^{\bullet}$ & $21,80^{\mathbf{\Lambda}}$ & $22,88^{\bullet}$ & 1,02 \\
\hline M. Kirizawa et al. 1057 & $22,32 \bullet$ & $26,28^{\bullet}$ & $23,73^{\bullet}$ & 0,85 \\
\hline \multicolumn{5}{|l|}{ B. umbrosa } \\
\hline M. Kuhlmann 2903 & $19,69^{\bullet}$ & $21,95^{\bullet}$ & $21,47^{\bullet}$ & 0,89 \\
\hline W. Mantovani 154 & $20,94^{\bullet}$ & $22,96^{\bullet}$ & $21,97^{\bullet}$ & 0,91 \\
\hline \multicolumn{5}{|l|}{ N. primulifolius } \\
\hline C. Kameyama et al. 113 & $16,35^{\wedge}$ & $17,61^{\bullet}$ & $16,94^{\bullet}$ & 0,93 \\
\hline
\end{tabular}

O. Yano 781 de Besleria longimucronata e M. Kirizawa et al. 1057 de Besleria selloana, apresentam grãos de pólen suboblatos enquanto que o espécime $M$. Kirizawa et al. 1017 de Besleria selloana está na classe de grãos de pólen prolato-esferoidais, diferenciando-se assim, dos respectivos materiais padrão analisados.

Para a análise de componentes principais (PCA) foram utilizadas 7 variáveis métricas dos grãos de pólen (tabela 4): Diâmetro Polar e Equatorial em Vista Equatorial (DPVE e DEVE), Diâmetro Equatorial em Vista Polar (DEVP), Comprimento e Largura do Colpo (CCOM e CLAR), Comprimento e Largura da 

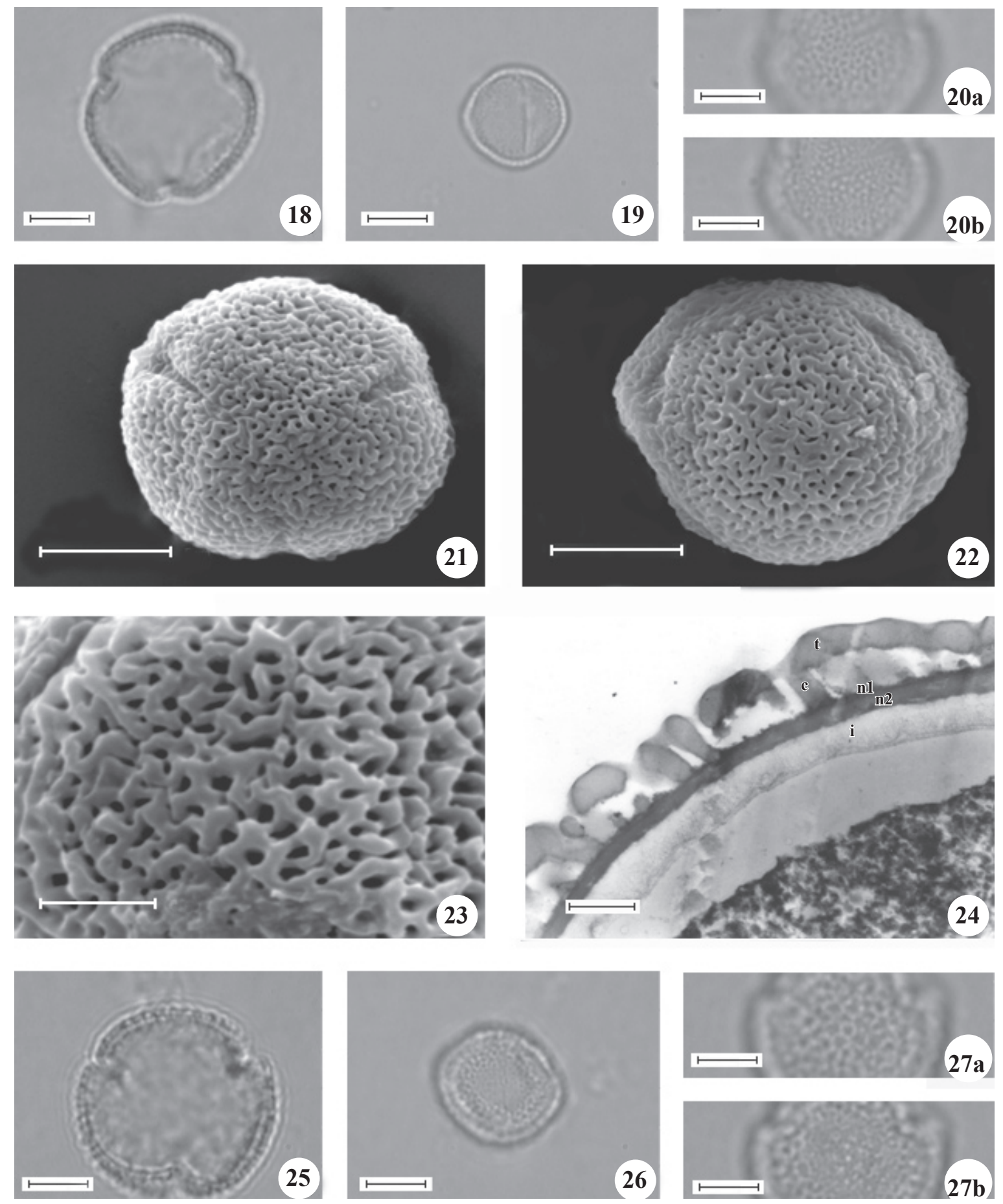

Figuras 18-27. Fotomicrografias e eletromicrografias (MEV e MET) dos grãos de pólen de espécies de Napeanthus. 18-24. Napeanthus primulifolius. 18. Vista polar. 19. Vista equatorial. 20. Análise de L.O. 21. Vista polar (MEV). 22. Vista equatorial (MEV). 23. Detalhe da ornamentação $(\mathrm{MEV}) .24$. Detalhe da estrutura da parede da exina, sob MET $(\mathrm{t}=$ teto; $\mathrm{c}=$ columela; $\mathrm{n} 1=$ nexina $1 ; \mathrm{n} 2=$ nexina 2; $\mathrm{i}=$ intina). 25-27. Napeanthus reitzii. 25. Vista polar. 26. Vista equatorial. 27. Análise de L.O. Barra $=5 \mu \mathrm{m}(18,20-22,25,27) ; 10 \mu \mathrm{m}(19,26) ; 2 \mu \mathrm{m}(23) ; 750 \mathrm{~nm}(24)$.

Figures 18-27. Light, scanning and transmition electron micrographs of pollen grains of Napeanthus Gardn. 18-24. Napeanthus primulifolius. 18. Polar view. 19. Equatorial view. 20. Analysis of L.O. 21. Polar view (SEM). 22. Equatorial view (SEM). 23. Detail of ornamentation (SEM). 24. Detail of pollen wall structure in TEM ( $\mathrm{t}=$ tectum; $\mathrm{c}=$ columella; $\mathrm{n} 1=$ nexine $1 ; \mathrm{n} 2=$ nexine $2 ; \mathrm{i}=$ intine). 25-27. Napeanthus reitzii. 25. Polar view. 26. Equatorial view. 27. Analysis of L.O. Bar $=5 \mu \mathrm{m}(18,20-$ 22, 25, 27); $10 \mu \mathrm{m}(19,26) ; 2 \mu \mathrm{m}(23) ; 750 \mathrm{~nm}$ (24).. 
Endoabertura (ECOM e ELAR). A PCA resumiu em seus dois primeiros eixos (figura 29) 94,7\% da variabilidade total dos dados.

O primeiro eixo resumiu sozinho $84,27 \%$ da variância em função dos valores altamente relacionados principalmente do comprimento e largura dos colpos dos grãos de pólen (figura 29). No lado esquerdo do eixo foram ordenadas as espécies de Besleria associadas aos altos valores das variáveis métricas de seus grãos de pólen. Diferentemente, as espécies de Napeanthus foram ordenadas no lado direito do eixo, associadas aos menores valores nas variáveis.

Chave polínica para espécies dos gêneros Besleria L. e Napeanthus Gardn. no Estado de São Paulo

1. Grãos de pólen psilado-perfurados ou rugulados

2. Grãos de pólen psilado-perfurados; colpos com extremidades afiladas; endoaberturas lolongadas

B. longimucronata

2. Grãos de pólen rugulados; colpos com extremidades arredondadas; endoaberturas subcirculares

B. umbrosa

1. Grãos de pólen microrreticulados

3. Microrretículos homobrocados; muros retos; colpos largos $(>2,00 \mu \mathrm{m})$ B. selloana

3. Microrretículos heterobrocados; muros sinuosos; colpos estreitos $(<2,00 \mu \mathrm{m})$ N. primulifolius

N. reitzii
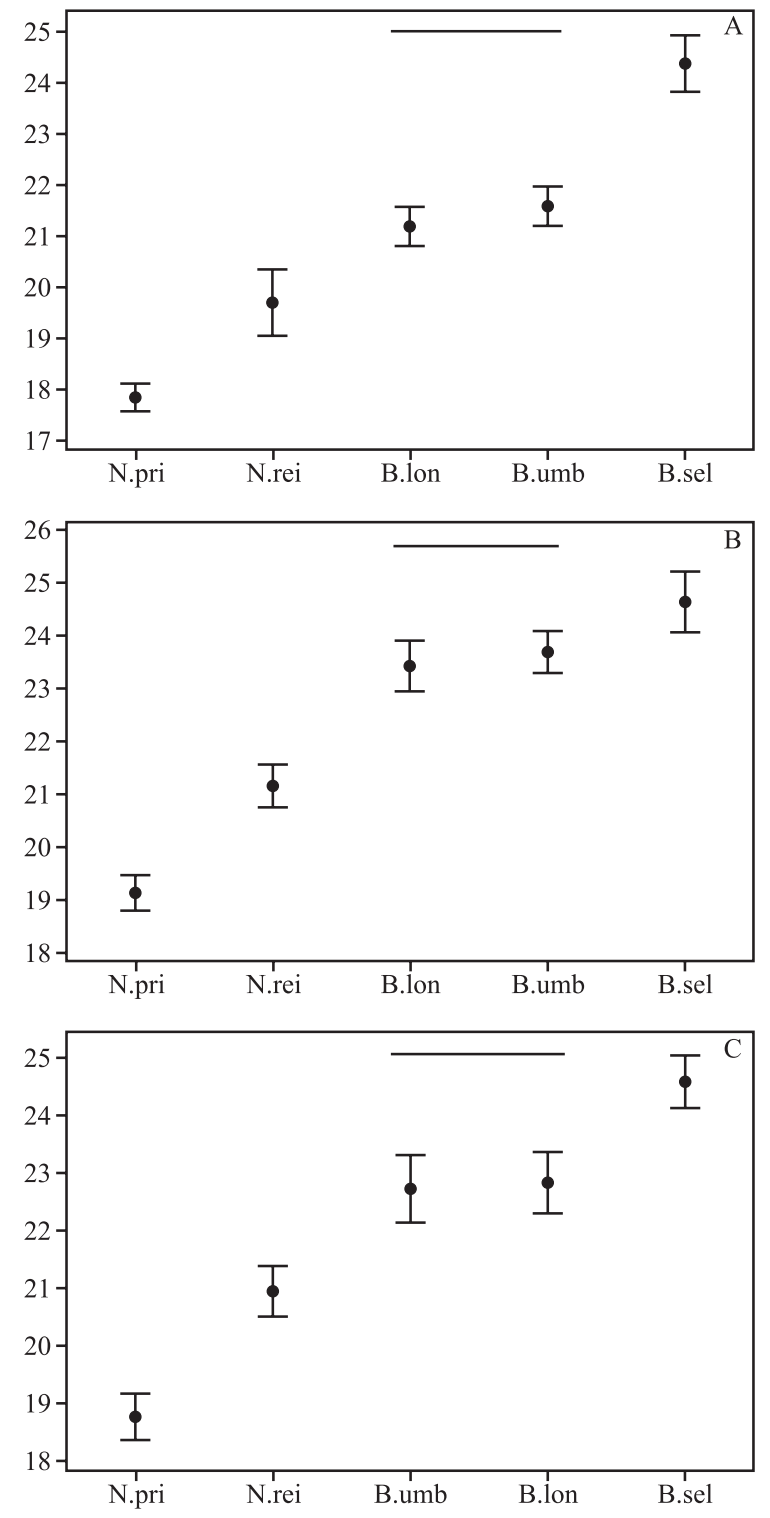

\section{Discussão}

Existem poucos dados na literatura palinológica para os grãos de pólen de espécies brasileiras de Gesneriaceae, apenas os trabalhos de Campos (1962), Melhem \& Mauro (1973), Williams (1978), Felice et al. (1981), Melhem et al. (2003) e Fourny et al. (2010).

Besleria longimucronata e B. umbrosa foram examinadas palinologicamente por Fourny et al. (2010) ao estudarem as espécies de Gesneriaceae ocorrentes no Estado do Rio de Janeiro. As autoras descreveram para as espécies, grãos de pólen pequenos, isopolares, prolatos,

Figura 28. Representação gráfica do intervalo de confiança da média a 95\% dos grãos de pólen de espécies de Besleria e Napeanthus. A. Diâmetro polar em vista equatorial. B. Diâmetro equatorial em vista equatorial. C. Diâmetro equatorial em vista polar. Os limites superiores e inferiores representam o intervalo de confiança; os círculos medianos representam a média aritmética. As linhas horizontais na parte superior representam o resultado do teste de Tukey. (Npri = Napeanthus primulifolius; $\mathrm{Nrei}=N$. reitzii $;$ Blon $=$ Besleria longimucronata , Bumb $=$ B. umbrosa $;$ Bsel $=$ B. selloana . Os valores são dados em $\mu \mathrm{m}$.

Figure 28. Representation of mean confidence interval of in $95 \%$ of pollen grains of Besleria e Napeanthus. A. Polar diameter in equatorial view. B. Equatorial diameter in equatorial view. C. Equatorial diameter in polar view. The higher and lower boundaries showing the confidence interval; the average circle showing the arithmetic mean. (Npri = Napeanthus primulifolius; $\mathrm{Nrei}=N$. reitzii $; \mathrm{Blon}=$ Besleria longimucronata $; \mathrm{Bumb}=$ B. umbrosa $; \mathrm{Bsel}=$ B. selloana . The values is in $\mu \mathrm{m}$. 
Tabela 4. Coeficientes de correlação de Pearson e Kendall entre as variáveis métricas dos grãos de pólen e os dois primeiros eixos da ordenação pela PCA para as espécies estudadas de Besleria L. e Napeanthus Gardn.

Table 4. Pearson and Kendall coefficients for pollen grain metric variables of the first two axis of PCA ordination of Besleria L. and Napeanthus Gardn.

\begin{tabular}{llrr}
\hline \multirow{2}{*}{ Variáveis } & & \multicolumn{2}{c}{$\begin{array}{c}\text { Componentes } \\
\text { Principais }\end{array}$} \\
\cline { 3 - 4 } & & Eixo 1 & Eixo 2 \\
\hline DEVP & $\begin{array}{c}\text { (diâmetro equatorial em vista } \\
\text { polar) }\end{array}$ & $-0,316$ & 0,078 \\
DPVE & $\begin{array}{c}\text { (diâmetro polar em vista } \\
\text { equatorial) }\end{array}$ & $-0,350$ & $-0,097$ \\
DEVE & $\begin{array}{c}\text { (diâmetro equatorial em vista } \\
\text { equatorial) }\end{array}$ & $-0,314$ & 0,107 \\
CCOM & $\begin{array}{c}\text { (comprimento do colpo) } \\
\text { CLAR }\end{array}$ & $-0,486$ & $-0,092$ \\
ECOM & $\begin{array}{c}\text { (comprimento da } \\
\text { endoabertura) }\end{array}$ & $-0,406$ & $-0,757$ \\
ELAR & (largura da endoabertura) & $-0,268$ & 0,309 \\
\hline
\end{tabular}

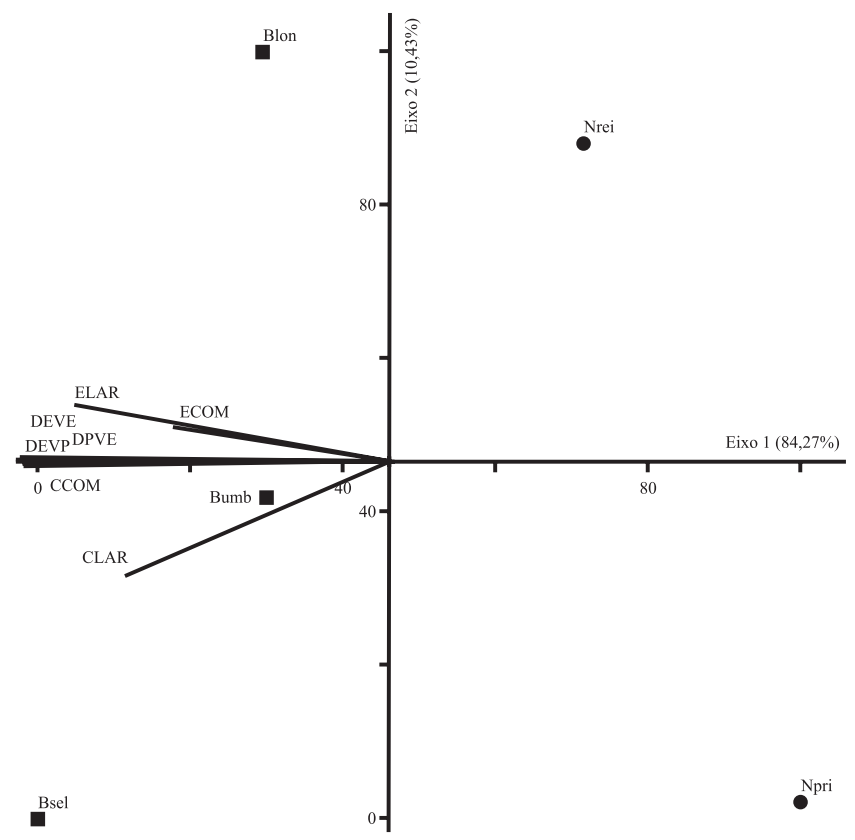

Figura 29. Ordenação, pela PCA, das espécies de Besleria e Napeanthus, em função das variáveis métricas dos grãos de pólen [Tabela 4]. (Blon = Besleria longimucronata $;$ Bsel $=B$. selloana $; \mathrm{Bumb}=$ B. umbrosa $; \mathrm{Npri}=$ Napeanthus primulifolius; Nrei $=$ N. reitzii; $\mathbf{\square}=$ Besleria $; \boldsymbol{\bullet}=$ Napeanthus $)$.

Figure 29. Biplot of PCA for Besleria and Napeanthus species, of ate pollen grain metric variables. $($ Blon $=$ Besleria longimucronata; Bsel = B. selloana; Bumb = B. umbrosa; Npri $=$ Napeanthus primulifolius; Nrei $=N$. reitzii; $\mathbf{\square}=$ Besleria; = Napeanthus). tectado-perfurados, 3-colpados e subtriangulares em $B$. longimucronata, 3-colporados e subcirculares em $B$. umbrosa. Os resultados aqui encontrados divergiram quanto a forma (oblato-esferoidal nas duas espécies), a abertura e o âmbito em $B$. longimucronata (3-colporada e circular), e a ornamentação em B. umbrosa. No presente estudo os grãos de pólen desta última espécie são descritos como rugulados, pois foram observadas ondulações conspícuas espalhadas por toda a superfície do grão de pólen, o que também foi descrito por Fourny et al. (2010).

Roubik \& Moreno (1981) ao estudarem os grãos de pólen, sob microscopia de luz, de 10 espécies da família Gesneriaceae da Ilha de Barro Colorado (Panamá) observaram em Besleria laxiflora grãos de pólen subprolatos a esferoidais, com exina psilada e diâmetro variando entre 23-25 $\mu \mathrm{m}$. Das três espécies de Besleria aqui estudadas, somente $B$. longimucronata apresentou ornamentação psilado-perfurada semelhante, portanto, à ornamentação encontrada para Besleria laxiflora, por Roubik \& Moreno (1991), os quais mencionam, ainda, a presença de membrana granular persistente no colpo; essa característica, também foi observada, nos espécimes aqui estudados tanto de Besleria quanto de Napeanthus. Os valores dos diâmetros dos grãos de pólen de Besleria laxiflora, encontrados por Roubik \& Moreno (1991), são similares aos aqui encontrados para as espécies de Besleria.

Williams (1978) estudou 30 espécies neotropicais da subfamília Gesnerioideae analisando os grãos de pólen de quatro tribos, dentre as quais Napeantheae, com uma única espécie. $\mathrm{O}$ autor mencionou que os grãos de pólen de Napeanthus costaricensis são isopolares, reticulados. No presente estudo, os grãos de pólen das espécies $N$. primulifolius e $N$. reitzii também se apresentaram isopolares, mas com ornamentação microrreticulada.

Com base nos resultados aqui obtidos para as espécies dos gêneros Besleria e Napeanthus (tribos Beslerieae/Napeantheae) constatou-se a variabilidade quanto à ornamentação da exina, confirmando os dados de literatura para a família Gesneriaceae (Melhem \& Mauro 1973, Salgado-Labouriau 1973, Skog 1976, Williams 1978, Roubik \& Moreno 1991, Luegmayr 1993a, b, Palee et al. 2003 e Fourny et al. 2010).

Luegmayr (1993b) ao estudar 108 espécies da subfamília Cyrtandroideae do Velho Mundo sob microscopia de luz, e eletrônica de varredura e de transmissão, estabeleceu 10 tipos polínicos com base na ornamentação da exina. Com a finalidade de comparar os grãos de pólen de 34 espécies de Cyrtandroideae da Tailândia e do Laos, Palee et al. (2003) seguiram, com 
algumas modificações, a classificação dos tipos de exina estabelecidos por Luegmayr (1993b), acrescentando a estes mais cinco tipos polínicos. Desta forma, considerando os 15 tipos de Palee et al. (2003), podese enquadrar as espécies aqui estudadas de Napeanthus: $N$. primulifolius e N. reitzii, no tipo 1 (ornamentação reticulado-microrreticulada, com lúmens heterobrocados tanto no apocolpo quanto no mesocolpo e sem elementos supratectais). Besleria longimucronata enquadra-se no tipo 8 (com ornamentação perfurada tanto no apocolpo quanto no mesocolpo e sem elementos supratectais), Besleria umbrosa no tipo 10 (com rúgulas tanto no apocolpo quanto no mesocolpo) e Besleria selloana no tipo 11 (com ornamentação microrreticulada e lúmens homobrocados tanto no apocolpo quanto no mesocolpo, sem elementos supratectais).

Os dados da literatura mostram que ornamentação microrreticulada e reticulada são muito comuns nos grãos de pólen da família Gesneriaceae, podendo ocorrer nos gêneros Cyrtandra (Luegmayr 1993a, b, Schlag-Edler \& Kiehn 2001), Chirita, Didymocarpus, Streptocarpus, (Luegmayr 1993b, Palee et al. 2003), Asteranthera, Seemannia, Sinningia (Felice et al. 1981), Monophyllaea (Luegmayr 1993b), Aeschynanthus, Leptoboea, Lysionotus, Oreocharis, Rhynchoglossum, Rhynchotechum e Stauranthera (Palee et al. 2003), Codonanthe, Paliavana e Sinningia (Fourny et al. 2010).

Taxonomicamente, as espécies aqui estudadas do gênero Besleria, encontram-se na seção Eubesleria (Hanst.) Benth. \& Hook., B. selloana e B. umbrosa na subseção Elongatae e $B$. longimucronata na subseção Mirificae (Morton 1939). Estas espécies, segundo Chautems \& Matsuoka (2003), apresentam morfologia externa bastante similar, sendo separadas somente por características da inflorescência pedunculada ou séssil/subséssil em $B$. longimucronata e pelo número de flores por inflorescência, 2-3 flores em $B$. umbrosa e 6-12 flores em $B$. selloana. Através da ornamentação da exina dos grãos de pólen é possível distinguir as três espécies de Besleria evidenciando-se, dessa forma, o caráter euripolínico do gênero, mas as características que permitiram a separação das espécies não permitiram separá-las de acordo com as subseções.

A tribo Napeantheae é monotípica, o único gênero Napeanthus, tem duas espécies nativas no Brasil: Napeanthus primulifolius, ocorrente nos Estados de Rio de Janeiro, São Paulo e marginalmente no Paraná, e N. reitzii, nos Estados do Paraná e Santa Catarina (Leeuwenberg (1958), A. Chautems, dados não publicados). Com base principalmente em dados moleculares, Smith (2000) e Zimmer et al. (2002) verificaram que Napeantheae e
Beslerieae são tribos muito relacionadas, formando um clado irmão dos outros representantes de Gesnerioideae. Apesar de somente duas espécies terem sido tratadas neste trabalho, verificou-se que os grãos de pólen de Napeanthus primulifolius e $N$. reitzii são muito similares e a separação dessas espécies ocorreu, apenas, com base em dados quantitativos, o que indica, possivelmente, que a morfologia polínica seja constante no gênero.

Aordenação obtida através da análise de componentes principais dos grãos de pólen das espécies de Besleria e Napeanthus estudadas corroborou os dados quantitativos dos grãos de pólen permitindo separar as espécies, em função das maiores medidas para os grãos de pólen de Besleria e as menores em Napeanthus.

A diferença morfológica para os grãos de pólen, tanto em relação ao tamanho dos grãos de pólen quanto à ornamentação da exina, revelou-se um caráter importante, principalmente em nível específico, para o posicionamento das espécies. Apesar de restrito a táxons nativos do Estado de São Paulo (exceto $N$. reitzii), os dados da morfologia polínica em Beslerieae e Napeantheae corroboram o reconhecimento destas tribos como propostas por Wiehler (1983), Smith (1996) e Smith et al. (1997), e Zimmer et al. (2002). Pode-se concluir, então, que a morfologia polínica é um bom recurso para a taxonomia dos gêneros de Gesneriaceae estudados.

Agradecimentos - $\grave{A}$ Capes (Coordenadoria de Aperfeiçoamento de Pessoal de Nível Superior), pela bolsa de mestrado concedida ao primeiro autor. Aos estagiários Priscila Rodrigues (Instituto de Botânica) e Ricardo Lombardi (Instituto Biológico), pelos auxílios laboratoriais.

\section{Referências bibliográficas}

BARROSO, G.M., PEIXOTO, A.L., ICHASO, C.L., COSTA, C.G., GUIMARÃES, E.F. \& LIMA, H.C. 1986. Sistemática de angiospermas do Brasil. Universidade Federal de Viçosa, Imprensa Universitária, Viçosa, v.3.

BARTH, O.M. \& MELHEM, T.S. 1988. Glossário ilustrado de palinologia. Editora da Universidade Estadual de Campinas, Campinas.

BENTHAM, G. 1846. Plantas hartwegianae. W. Pamplin, London.

BENTHAM, G. 1876. Gesneriaceae. In Genera plantarum (G. Bentham \& J.D. Hooker, eds.). Lovell Reeve \& Company, London, p.990-1025.

BURTT, B.L. \& WIEHLER, H. 1995. Classification of the family Gesneriaceae. Gesneriana 1:1-4.

CAMPOS, S.M. 1962. Pollen grains of plants of the "Cerrado" - IV. Revista Brasileira de Biologia 22:307-315. 
CHAUTEMS, A. 1991. A família Gesneriaceae na região cacaueira da Bahia, Brasil. Revista Brasileira de Botânica 14:51-59.

CHAUTEMS, A. 2003. Gesneriaceae. In Flora do Distrito Federal (T.B. Cavalcanti \& A.E. Ramos, coords.). Embrapa, Brasília, v.3, p.185-197.

CHAUTEMS, A. \& MATSUOKA, C.Y.K. 2003. Gesneriaceae. In Flora Fanerogâmica do Estado de São Paulo (M.G.L. Wanderley, G.J. Shepherd, A.M. Giulietti \& T.S. Melhem, (coords.). Fapesp/Rima, São Paulo, v.3, p.75-103.

ERDTMAN, G. 1952. Pollen morphology and plant taxonomy - Angiosperms. Almqvist \& Wiksell, Stockholm.

ERDTMAN, G. 1960. The acetolysis method. A revised description. Svensk Botanisk Tidskrift 54:561-564.

FAEGRI, G. \& IVERSEN, J. 1966. Textbook of modern pollen analysis. $2^{\text {nd }}$ ed. Scandinavian University Books, Copenhagen.

FELICE, M.A.C., SANCHIS, A.M. \& VILLAR, L.M. 1981. Granos de pólen de las Gesneriaceae de la Argentina. Comunicaciones del Museo Argentino de Ciencias Naturales "Bernardino Rivadavia" 2:77-89.

FEUILLET, C. \& SKOG, L.E. 2002. Novae Gesneriaceae Neotropicarum XII. New species of Gesneriaceae from the Guianas. Brittonia 54:353-361.

FOURNY, A.C.S., MENDONÇA, C.B.F., LOPES, T.C.C. \& GONÇALVES-ESTEVES, V. 2010. Palinologia de espécies de Gesneriaceae Rich. \& Juss. ocorrentes no Estado do Rio de Janeiro, Brasil. Acta Botanica Brasilica 24:812-824.

FRITZE, K.J. \& WILLIAMS, N.H. 1988. The taxonomic significance of pollen morphology in the Columnea alliance (Gesneriaceae: Gesnerioideae). Annals of the Missouri Botanical Garden 75:168-191.

HADDAD, A., SESSO, A., ATTIAS, M., FARINA, M., MEIRELLES, M.N., SILVEIRA, M., BENCHIMOL, M., SOARES, M.J., BARTH, O.M., MACHADO, R.D., SOUTO-PADRÓN, T. \& SOUZA, W. 1998. Técnicas básicas de microscopia eletrônica aplicadas às Ciências Biológicas. Sociedade Brasileira de Microscopia, Rio de Janeiro.

HANSTEIN, I. 1865. Die Gesneraceen des Königlichen Herbariums und der Gärten zu Berlin, nebst Uebersicht der Familie im Ganzen, II: Gattungen und Arten, 3: Die Eugesnereen, Rhytidophylleen und Beslerieen. Linnaea 34:225-446.

HOWARD, R.A. 1975. The genus Anetanthus (Gesneriaceae). Journal of Arnold Arboretum 56:364-368.

LEEUWENBERG, A.J.M. 1958. Revision of Napeanthus. Acta Botanica Neerlandica 7:340-354.

LUEGMAYR, E. 1993a. Pollen of Hawaiian Cyrtandra (Gesneriaceae) including notes on southeast Asian taxa. Blumea 38:25-38.

LUEGMAYR, E. 1993b. Pollen characters of Old World Gesneriaceae (Cyrtandroideae). Grana 32:221-232.
MCCUNE, B. \& MEFFORD, M.J. 1999. PC-ORD. Multivariate analysis of ecological data. MjM Software Design, Oregon.

MEIRELLES, S.T., PIVELLO, V.R. \& JOLY, C.A. 1999. The vegetation of granite rock outcrops in Rio de Janeiro, Brazil, and the need for its protection. Environmental Conservation 26:10-20.

MELHEM, T.S. \& MAURO, C. 1973. Pollen morphological studies in Gesneriaceae. Hoehnea 3:13-27.

MELHEM, T.S., CRUZ-BARROS, M.A.V., CORRÊA, A.M.S., MAKINO-WATANABE, H., SILVESTRECAPELATO, M.S.F. \& GONÇALVES-ESTEVES, V.L. 2003. Variabilidade polínica em plantas de Campos do Jordão (São Paulo, Brasil). Boletim do Instituto de Botânica de São Paulo 16:1-104.

MINITAB INC. 2003. Minitab for windows. Versão 10.3 Minitab Inc, State College.

MORTON, C.V. 1939. A revision of Besleria. Contributions from the United States National Herbarium 26: 395-474.

NOWICKE, J.W. 1974. Two new species of Besleria (Gesneriaceae) from Panama. Brittonia 26:37-41.

PALEE, P., SAMPSON, F.B. \& ANUSARNSUNTHORN, V. 2003. Pollen morphology of some Thai Gesneriaceae. The Natural History Bulletin of Siam Society 51: 225-240.

PUNT, W., HOEN, P.P., BLACKMORE, S., NILSSON, S. \& LE THOMAS, A. 2007. Glossary of pollen and spore terminology. Review of Paleobotany and Palynology 143:1-81.

ROALSON, E.H., BOGGAN, J.K., SKOG, L.E. \& ZIMMER, E.A. 2005a. Untangling Gloxinieae (Gesneriaceae). I. Phylogenetic patterns and generic boundaries inferred from nuclear, chloroplast, and morphological cladistic datasets. Taxon 54:389-410.

ROALSON, E.H., BOGGAN, J.K. \& SKOG, L.E. 2005 b. Reorganization of tribal and generic boundaries in the Gloxinieae (Gesneriaceae: Gesnerioideae) and the description of new tribe in the Gesnerioideae Sphaerorrhizeae. Selbyana 25:225-238.

ROUBIK, D.W. \& MORENO, P.J.E. 1991. Pollen and spores of Barro Colorado Island. Monograph in Systematic Botany. Missouri Botanical Garden 36:1-268.

SABATINI, D.D., BENSCH, K. \& BARRNETT, R.J. 1963. Cytochemistry and electron microscopy: the preservation of cellular ultrastructure and enzymatic activity by aldehyde fixation. Journal of Cellular Biology 17: 19-58.

SAFFORD, H.D. \& MARTINELLI, G. 2000. Southeast Brazil. In Inselbergs: biotic diversity of isolated rock outcrops in tropical and temperate regions (S. Porembski \& W. Barthlott, eds.). Springer-Verlag, Berlin, p.339-389.

SALGADO-LABOURIAU, M.L. 1973. Contribuição à palinologia dos Cerrados. Academia Brasileira de Ciências, Rio de Janeiro. 
SALGADO-LABOURIAU, M.L., VANZOLINI, P.E. \& MELHEM, T.S. 1965. Variation of polar axes and equatorial diameters in pollen grains of two species of Cassia. Grana Palynologica 6:98-105.

SCHLAG-EDLER, B. \& KIEHN, M. 2001. Palynology of South Pacific Cyrtandra (Gesneriaceae) with notes on some Hawaiian taxa. Grana 40:192-196.

SHEPHERD, G.J. 1996. Fitopac 1: manual do usuário. Departamento de Botânica, Universidade Estadual de Campinas, Campinas.

SKOG, L.E. 1976. A study of the tribe Gesnerieae, with a revision of Gesneria (Gesneriaceae: Gesnerioideae). Smithsonian Contributions to Botany 29:1-182.

SKOG, L.E. \& JESUS, F.F. 1997. A review of Resia (Gesneriaceae). Biollania, Edición Especial 6:515525.

SKOG, L.E. \& KVIST, L.P. 2000. Revision of Gasteranthus (Gesneriaceae). Monograph in Systematic Botany. Missouri Botanical Garden 59:1-118.

SMITH, J.F. 1996. Tribal relationships within Gesneriaceae: a cladistic analysis of morphological data. Systematic Botany 21:497-513.

SMITH, J.F. 2000. Phylogenetic resolution within the tribe Episcieae (Gesneriaceae): congruence of ITS and $n d h \mathrm{~F}$ sequences from parsimony and maximum-likelihood analyses. American Journal of Botany 87:883-897.

SMITH, J.F., WOLFRAM, J.C., BROWN, K.D., CARROL, C.L. \& DENTON, D.S. 1997. Tribal relationships in the Gesneriaceae: evidence from DNA sequences of the chloroplast gene ndhF. Annals of the Missouri Botanical Garden 84:50-66.
VIEIRA, S. 1981. Introdução à bioestatística. Campus, Rio de Janeiro.

WEBER, A. 2004a. Gesneriaceae. In The families and genera of vascular plants (K. Kubitzki \& J. W. Kadereit, eds.). Springer Verlag, Berlin, v.7, p.63-158.

WEBER, A. 2004b. Research on Gesneriaceae in Austria Part IV: recent and present work. Gloxinian 54:44-53.

WIEHLER, H. 1975. Besleria L. and the re-establisnment of Gasteranthus Benth. (Gesneriaceae). Selbyana 1:150156.

WIEHLER, H. 1983. A synopsis of the neotropical Gesneriaceae. Selbyana 6:1-219.

WILLIAMS, N.H. 1978. Pollen structure and the systematics of the neotropical Gesneriaceae. Selbyana 2:310-322.

XIFREDA, C.C. 1996. Citas nuevas o críticas para la flora Argentina II: Gloxinia gymnostoma y G. nematanthodes (Gesneriaceae). Darwiniana 34:383-388.

ZHI-JIAN, Y., ZHEN-YU, L. \& FU-HSIUNG, W. 1995. Pollen morphology of tribe Klugieae (Gesneriaceae) in China. Cathaya 7:99-104.

ZHI-JIAN, Y., ZHEN-YU, L. \& FU-HSIUNG, W.1997. Pollen morphology of tribe Trichosporeae (Gesneriaceae) in China and its systematic significance. Harvard Papers of Botany 10:113-120.

ZAR, J.H. 1996. Biostatistical analysis. Prentice Hall/ Englewood Cliffs, New Jersey.

ZIMMER, E.A., ROALSON, E.H., SKOG, L.E., BOGGAN, J.K. \& IDNURM, A. 2002. Phylogenetic relationships in the Gesnerioideae (Gesneriaceae) based on nrDNA ITS and $c p D N A$ trn $\mathrm{L}-\mathrm{F}$ and $t r n \mathrm{E}-\mathrm{T}$ spacer region sequences. American Journal of Botany 89:296-311. 
